\title{
Controlling Synthesis of Polymer-Derived Carbon Molecular Sieve and its Performance for $\mathrm{CO}_{2} / \mathrm{CH}_{4}$ Separation
}

\author{
Imam Prasetyo ${ }^{1, a}$, Rochmadi $^{1}$, Endro Wahyono ${ }^{1}$ and Teguh Ariyanto ${ }^{1,2, b, *}$ \\ 1 Chemical Engineering Department, Universitas Gadjah Mada, Jl. Grafika 2, 55281 Yogyakarta, \\ Indonesia \\ 2 Lehrstuhl für Chemische Reaktionstechnik, Friedrich-Alexander-Universität Erlangen-Nürnberg (FAU), \\ Egerlandstrasse 3, 91058 Erlangen, Germany \\ E-mail: aimampras@ugm.ac.id, bariyanto.teguh@fau.de (Corresponding author)
}

\begin{abstract}
Due to its specific micropore structure, carbon molecular sieve (CMS) can provide more selective properties than conventional activated carbon in adsorbing molecule from a gaseous mixture. In this research, preparation of CMS for $\mathrm{CO}_{2} / \mathrm{CH}_{4}$ separation has been developed by pyrolysis of specially synthesized polymeric resins as the precursor. This research was particularly focused on the development of precursor for the control of carbon microporosity to enhance the sieving properties. Precursor was synthesized through polymerization reaction of phenol with formaldehyde and p-tertbutyl phenol using acid catalyst in a batch reactor. Pyrolysis of the polymeric precursors was carried out in a retort at $450-850{ }^{\circ} \mathrm{C}$ in flowing $\mathrm{N}_{2}$ inert gas at flow rate of 100 $\mathrm{mL} / \mathrm{h}$ for 1.5 hours. The resulting micropore size and surface area of the carbon were characterized using $\mathrm{N}_{2}$-sorption analysis, whereas the carbon surface morphologies were observed using SEM. The carbons were further characterized for their uptake capacity and kinetic selectivity toward $\mathrm{CO}_{2}$ and $\mathrm{CH}_{4}$ gases. The results show that the porous carbon has suitable characteristic as sieving material for $\mathrm{CO}_{2} / \mathrm{CH}_{4}$ separation. In this work, CMS with kinetic selectivity $\left(D_{\mathrm{CO} 2} / D_{\mathrm{CH} 4}\right)$ as high as 8 , was produced.
\end{abstract}

Keywords: Carbon molecular sieve, phenolic resin, pyrolysis.

ENGINEERING JOURNAL Volume 21 Issue 4

Received 1 October 2016

Accepted 5 February 2017

Published 31 July 2017

Online at http://www.engj.org/

DOI:10.4186/ej.2017.21.4.83 


\section{Introduction}

Carbon dioxide removal from natural gas or biogas $\left(\mathrm{CH}_{4}\right.$ as the main component) is an important process in order to upgrade gas efficiency in industrial processes. Indeed, the presence of impurities like $\mathrm{CO}_{2}$ in natural gas decreases the heat content and consequently a low efficiency results. Thus, the low content of $\mathrm{CO}_{2}$ is necessary to obtain the high heating value of the fuel gas. Furthermore, a low portion of this impurity gas is required to suppress combination of carbon dioxide and water yielding an acidic character of gas flows [1]. This prevents corrosion e.g. in equipment and pipeline. For optimum gas utilization, the fraction of $\mathrm{CO}_{2}$ content in gas flow is limited to a 2 vol.\% concentration [2]. In this sense, an efficient and effective separation of $\mathrm{CO}_{2}$ from the main component of $\mathrm{CH}_{4}$ is required e.g. using the carbon molecular sieve (CMS) technology.

Carbon molecular sieve is a separation processes of gas mixtures based on the adsorption kinetic of the gas molecule in the porous material. This technique has been widely used in many chemical industries and become competitive to conventional separation process such as cryogenic distillation or absorption [3]. Due to its specific micropore structure, this porous carbon molecular sieve can provide more selective properties than conventional activated carbon in adsorbing molecule from a gaseous mixture [4-6]. With the micropore size in the range of molecular dimension, a small difference in size of molecules to be adsorbed will lead to a large difference in micropore diffusivities due to the activation energy required for diffusion. The utilization of CMS in gas separation processes is usually carried out in a couple of packed bed adsorption columns so called pressure swing adsorption (PSA) [7]. In addition to their application in separation processes, CMSs have been widely used as catalysts, and catalyst supports as well [8-12].

Efforts on preparation of carbon molecular sieve (CMS) have been performed by various research groups to search for effective and economical technologies for gas separation processes. Basically, carbonbased porous material such as CMS can be made by controlled pyrolysis of various natural carbonaceous materials such as coal, nut shell and wood [13-16] or synthetic polymer such as polyvinylidene chloride, polyimide and phenol formaldehyde [17-20]. It has been generally known that the pore structure of the carbon molecular sieve is affected by the nature of the precursor, pyrolysis method, and post-treatment conditions. The advantage of using synthetic polymer as a precursor for CMS preparation is that the pore structure of the carbon can be controlled during the precursor synthesis [21]. For instance, porous carbon derived from para-alkyl phenol formaldehyde has higher degree microporosity than that of conventional phenol formaldehyde [18, 22].

In this work, CMSs were prepared by controlled pyrolysis of specially synthesized polymeric resin as the precursor. The resin was synthesized through polymerization reaction of phenolic compound with formaldehyde under acidic condition. In fact, phenol formaldehyde resins have been increasingly used as precursor for porous carbon preparation due to its specific three dimensional structures of the polymer framework and thermosetting properties. However, in a very high temperature of pyrolysis and heat treatment processes, the structure of this polymeric precursor may collapse and lead to the decrease of the porosity of the carbon [22]. It is necessary, therefore, to synthesize precursor with a superior heat resistance. This kind of polymers is expected to retain its structural shape during heating and pyrolysis.

The objective of present work is to investigate para-tert-butyl phenol for enhancement of the thermosetting properties and polymer framework structures of phenol formaldehyde and to determine if this could produce any beneficial effects on the nature of the microporosity of the carbons produced from those polymeric precursors.

\section{Experimental}

\subsection{Precursor Synthesis}

Precursor was synthesized through polymerization reaction of phenol $(\mathrm{P})$ with formaldehyde $(\mathrm{F})$ and paratert-butyl phenol (TBP) under acidic conditions. The molar ratio of $\mathrm{P} / \mathrm{F} / \mathrm{TBP}$ was $0.7 / 3 / 0.3$. Reaction was carried out in a $500 \mathrm{~mL}$ batch reactor fitted with a reflux condenser, a mechanical stirrer, and thermometer. Conventional phenol formaldehyde with $\mathrm{P} / \mathrm{F}$ molar ratio of $1 / 3$ was prepared under the same condition for comparison with the investigated precursor. Concentrated hydrochloric acid and acetic acid were employed as a catalyst for the polymerization reaction. Phenol (with purity of $99 \%$ ), para-tert-butyl phenol (with purity of $99.5 \%$ ), and formaldehyde aqueous solution (as $36 \%$ formalin) were commercially obtained 
and used without further purification. Nitrogen gas with purity of $99.95 \%$ was supplied from a compressed gas cylinder as a carrier gas for carbonization processes and provides the inert atmospheric environment of the pyrolysis reaction as well.

\subsection{Precursor Carbonization}

The dried polymer was carbonized in a furnace under flowing nitrogen $(100 \mathrm{~mL} / \mathrm{min})$ from room temperature up to $1123 \mathrm{~K}$ at a heating rate of $10{ }^{\circ} \mathrm{C} / \mathrm{min}$ and kept at $1123 \mathrm{~K}$ for $1.5 \mathrm{~h}$. Then the furnace was allowed to cool down to room temperature under nitrogen flow and the obtained sample was washed with deionized distilled water. The degree of burnt-off, $\theta$ (weight \%) in this report is define as,

$$
\theta=\frac{W_{0}-W_{t}}{W_{0}} \times 100 \%
$$

where $W_{o}$ is the initial mass of the precursor and $W_{t}$ is the mass of the precursor after pyrolysis [23].

\subsection{Porous Carbon Characterization}

The surface morphologies of porous carbon materials were observed by JEOL JSM-6360LA analytical scanning electron microscope (SEM), and nitrogen adsorption was measured with a Nova 2000 adsorption analyzer (Quantachrome) at $77 \mathrm{~K}$. Prior to the measurement, sample was degassed at $400 \mathrm{~K}$ for $8 \mathrm{~h}$. The Brunauer-Emmett-Teller (BET) surface area was calculated from the adsorption data in the relative pressure $(p / p 0)$ interval from 0.05 to 0.35 . The total pore volume was estimated from the amount adsorbed at relative pressure of 0.99 . The pore size distribution of carbon was calculated using Howarth-Kawazoe (HK) method which typically employs to identify microporous structures. Ultra-high purity of compressed nitrogen $(99.9995 \%)$ was employed as the adsorbate for the $\mathrm{N}_{2}$-adsorption in the measurement of BET surface area and liquid nitrogen served as the coolant for measuring the $\mathrm{N}_{2}$-adsorption isotherms at $77 \mathrm{~K}$.

\subsection{Adsorption Test}

\subsubsection{Isotherms}

Adsorption capacity tests were carried out using the volumetric method at a constant temperature. CMS sample was first degassed at $523 \mathrm{~K}$ overnight until the static pressure in the system was at least $10^{-6} \mathrm{kPa}$. Isotherms of $\mathrm{CO}_{2}$ and $\mathrm{CH}_{4}$ were recorded in the range of $0-14 \mathrm{kPa}$. Henry constant $\left(K p^{*}\right)$ was determined from low adsorption isotherm data in the range of $0-1 \mathrm{kPa}$, using the following equation:

$$
q=K p^{*} \cdot P
$$

where $q$ is the equilibrium uptake and $P$ is the pressure.

\subsubsection{Kinetics}

Separation processes of gas mixtures using CMS was based on the adsorption kinetic of the gas molecule in that porous material. The kinetics of gas uptake measurement tests were performed in a semi-batch constant molar flow rate adsorber using a slab sample. The details of the experimental procedure of this technique are described in the previous work by Prasetyo and Do (1998) [24]. The apparent diffusivity $\left(D_{a p p}\right)$ of molecule through the CMS is valuated using the following equation (Eq. (3)). 


$$
\begin{aligned}
& P=\frac{(\dot{N}) R_{g} T / V}{(1+\beta)}+\frac{\beta}{(1+\beta)^{2}} \frac{\dot{N} R_{g} T}{(s+1)(s+3) D_{a p p}}-2(1+s) \beta\left[\left(\frac{\dot{N} R_{g} T}{V}\right)\left(\frac{R^{2}}{D_{a p p}}\right)\right] \times \\
& \sum_{n=0}^{\infty} \frac{\exp \left[-\lambda_{n}\left(D_{a p p} t / R^{2}\right)\right]}{\lambda_{n}^{2}\left[(1+s)^{2} \beta^{2}+(1+s)^{2} \beta+\lambda_{n}^{2}\right]}
\end{aligned}
$$

where $P$ is the pressure, $R_{g}$ is the ideal gas constant, $T$ is the temperature, $V$ is the volume of the adsorption cell excluding the volume of samples, $t$ is the adsorption time, $R$ is the particle radius, $s$ is the particle shape factor and $\beta$ is the equilibrium parameter. s and $\beta$ are defined as below:

$$
\beta=\frac{V_{a p p}}{V}=\left(\frac{m_{p}}{\rho_{p}}\right)\left(\frac{\varepsilon_{m}+\left(1-\varepsilon_{m}\right) K}{V}\right)
$$

where $m_{p}$ is the mass of particle, $\varrho_{p}$ is the particle density, $\varepsilon_{m}$ is the particle porosity, and $K$ is the dimensionless Henry constant. The eigenvalue $\lambda$ is obtained from the following transcendental equation for a slab shape $(s=0)$ :

$$
\beta \tan (\lambda)+\lambda=0
$$

\section{Results and Discussions}

The experimental work was carried out to prepare CMS by pyrolysis of specially synthesized phenol formaldehyde polymer as the precursor. The polymeric precursors were synthesized through polymerization reaction of phenol with formaldehyde and para-tert-butyl phenol under acidic conditions. The use of para-tert-butyl phenol in combination with phenol in the polymerization reaction was aimed to illustrate the role of the substitute phenol in enhancing certain properties of the precursor which lead to microporosity alteration of the carbonized precursor. In the case of polymerization reaction of formaldehyde with phenol only, the polymer structure has irregular network chain. Para-tert-butyl phenol was selected as the substitute phenol since the para-position of the butyl functional group in the phenol ring will direct the formaldehyde addition to ortho position only. Moreover, the para position of butyl functional group in this phenol derivative will create regular polymer network structures which could be beneficial for the production of carbon.

\subsection{Structural and Physical Properties of CMS Produced}

The SEM images were taken to study the effect of addition of para-tert-butyl phenol during the polymerization of phenolic resin on the surface morphologies of the resulting carbon. Figures 1(a) and 1(b) show the morphologic analysis for carbon derived from phenol formaldehyde polymer (CMS-1) as the reference and carbon derived from phenol formaldehyde $p$-tert-butyl phenol polymer (CMS-2), respectively. Both carbon samples were prepared in the same pyrolysis condition of $800^{\circ} \mathrm{C}$. It appears that the CMS-1 presents typical charcoal characteristics that are constituted by various fine particles [25]. Whereas, the carbon CMS-2 presents a smoother surfaces, but some fissures on the surface were observed. 


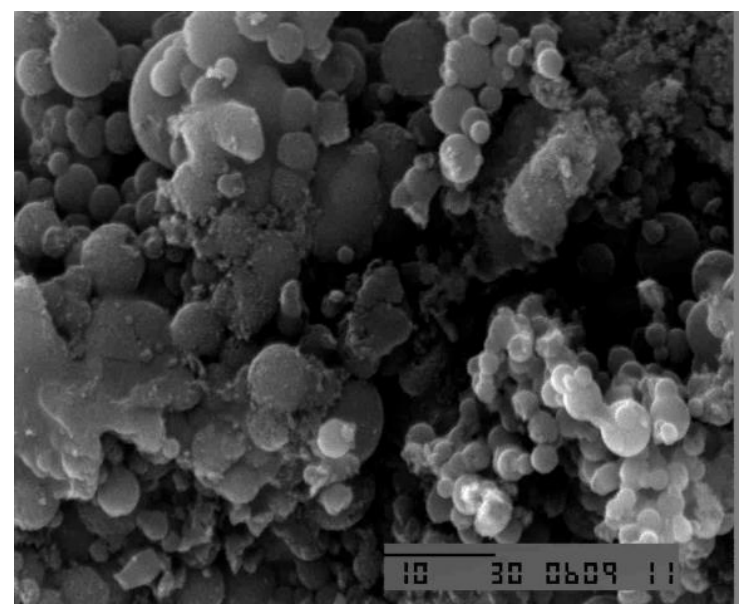

Fig. 1(a). SEM image of CMS-1 (derived from phenol-formaldehyde polymer).

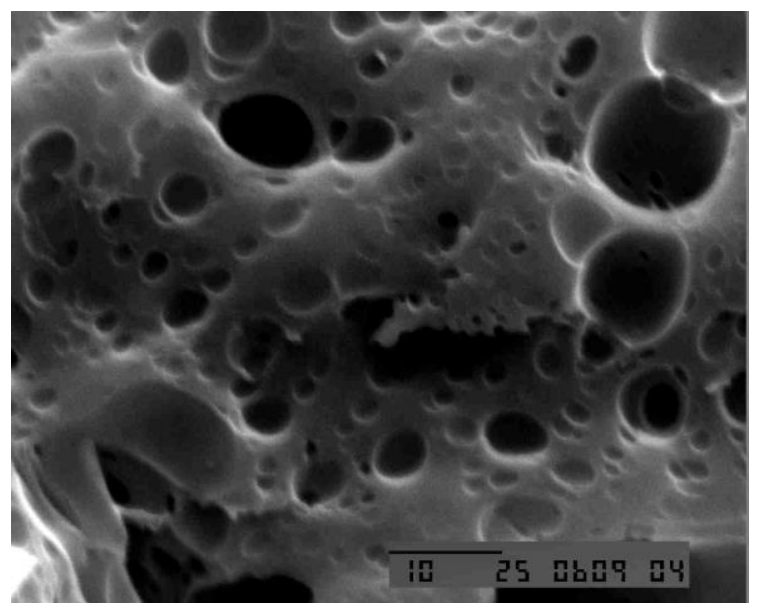

Fig. 1(b). SEM image of CMS-2 (derived from phenol-p-tert-butyl phenol-formaldehyde polymer).

The different in carbon surface morphology could be attributed to the nature of the polymeric precursor. Polymeric resin derived from phenol formaldehyde para-tert-butyl phenol was observed to be hard and tough, whereas the resin obtained from polymerization reaction of phenol with formaldehyde was exceedingly brittle. It is obvious that the structure and the properties of the polymeric product were affected by the type of phenol used. The effect of phenol type on the structure and the properties of the resin product can be explained by considering the processes involved in the polymerization reaction of the substitute phenol and the formaldehyde. The generally accepted mechanism of phenol formaldehyde polymerization reaction is that the reaction occurs by electrophilic aromatic substitution between the three active positions (two ortho-positions and one para-position) of phenol and the protonated formaldehyde, which can lead to produce irregular polymer network chain structure [26]. This is due to random link of methylene group to ortho and para positions in the phenol chain. Phenol and para-tert-butyl phenol will react with formaldehyde in a similar mechanism, but the presence of butyl functional group in para-position of the substitute phenol will direct the formation of polymer structures differently. Due to the presence of butyl functional group in para-position of the phenol ring, the substitution of formaldehyde will occur only at the two ortho-positions that lead to more regular structure of the polymer structure.

In this work, a series of carbons was derived from two different precursors at various carbonization temperatures. The micropore structure analysis by BET measurement of these carbons is listed in Table 1. The important aspect observed here is that loss in surface area of the CMS-1 at high temperature due to the thermal stability of the precursor. During the process of heat treatment, the polymer structure of phenolformaldehyde collapse. The idea of employing $p$-tert-butyl phenol in the preparation of phenolic polymer in this work is to develop thermally stable precursor. So when it is exposed to high temperature during the carbonization process only hydrogen and oxygen are removed in gaseous form by pyrolytic decomposition 
and left behind a rigid polymer network formed a microporous carbon material with fine pores. The data in Table 1 shows that PF polymer is more vulnerable to high temperature than that of PFTBP polymer. The burnt-off data in the table indicate that the weight loss during heat treatment is significant for PF polymer. The indication of the instability of the PF resin toward high temperature can also be observed from the surface area of the carbon produced. The surface area of the carbon derived from PF polymer at $800{ }^{\circ} \mathrm{C}$ and $850{ }^{\circ} \mathrm{C}$ carbonization temperature are 1883 and $1508 \mathrm{~m}^{2} / \mathrm{g}$, respectively. In contrast, pyrolysis of PFTBP polymer at $800^{\circ} \mathrm{C}$ and $850^{\circ} \mathrm{C}$ produced porous carbon with surface area of 1196 and $1774 \mathrm{~m}^{2} / \mathrm{g}$, respectively.

The properties of surface area of CMS produced $\left(1200-2000 \mathrm{~m}^{2} / \mathrm{g}\right)$ are in agreement with typically surface area of porous carbons synthesized by pyrolysis of polymeric materials [21, 25, 27]. But these values are superior to those values of porous carbons based on natural carbonaceous matters which are typically ca. $1000 \mathrm{~m}^{2} / \mathrm{g}$ (see Table 2, for the specific surface area comparison) [28-30]. Hence, a high quality of porous carbons results by the carbonization of phenol and or para-tert-butyl phenol resin. Moreover, the high surface areas obtained are comparable to novel porous carbon materials like carbide-derived carbons (CDC) with tuneable pore size [31-33].

Table 1. Effect of carbonization temperature on the burn-off and the pore textural parameters evaluated by $\mathrm{N}_{2}$-soption analysis.

\begin{tabular}{lcccc}
\hline \multicolumn{1}{c}{ Precursor } & $\begin{array}{c}\text { Carbonization } \\
\text { Temperature }\left[{ }^{\circ} \mathbf{C}\right]\end{array}$ & $\begin{array}{c}\text { Burn-Off } \\
{[\mathbf{\%}]}\end{array}$ & $\begin{array}{c}\text { Pore Volume } \\
{\left[\mathbf{c m}^{\mathbf{3}} \mathbf{\text { gram } ]}\right.}\end{array}$ & $\begin{array}{c}\text { BET surface area } \\
{\left[\mathbf{m}^{\mathbf{2}} / \mathbf{g r a m}\right]}\end{array}$ \\
\hline PF [CMS-1a] & 800 & 26 & 0.69 & 1883 \\
PF [CMS-1b] & 850 & 35 & 0.57 & 1508 \\
& & & & 1196 \\
PFTBP [CMS-2a] & 800 & 13 & 0.41 & 1774 \\
PFTBP [CMS-2b] & 850 & 14 & 0.65 & \\
\hline
\end{tabular}

To evaluate whether the carbonization has an influence on the pore structure, pore size distribution (PSD) of CMS-1 and CMS-2 synthesized at different temperature was evaluated from $\mathrm{N}_{2}$-sorption analysis using $\mathrm{HK}$ method. For carbonization at $800{ }^{\circ} \mathrm{C}$, both CMS-1 and CMS-2 possess almost a unimodal curve and a narrow pore size distribution. Furthermore, a remarkable high portion of pores at pore width below $0.8 \mathrm{~nm}$ (see Fig. 2 (a)) can be seen. At this temperature of $800{ }^{\circ} \mathrm{C}$, both CMSs show more or less comparable mean pore size of ca. $0.7 \mathrm{~nm}$.

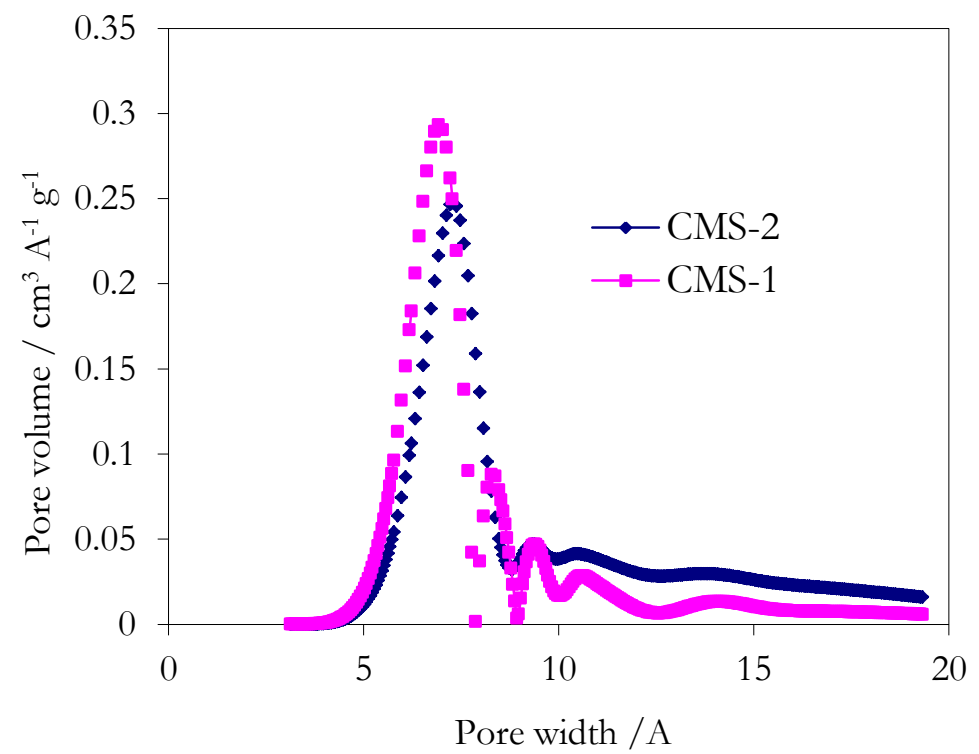

Fig. 2 (a). Pore size distribution of CMS-1 and CMS-2 produced by pyrolysis of phenolic polymers at $800^{\circ} \mathrm{C}$. 


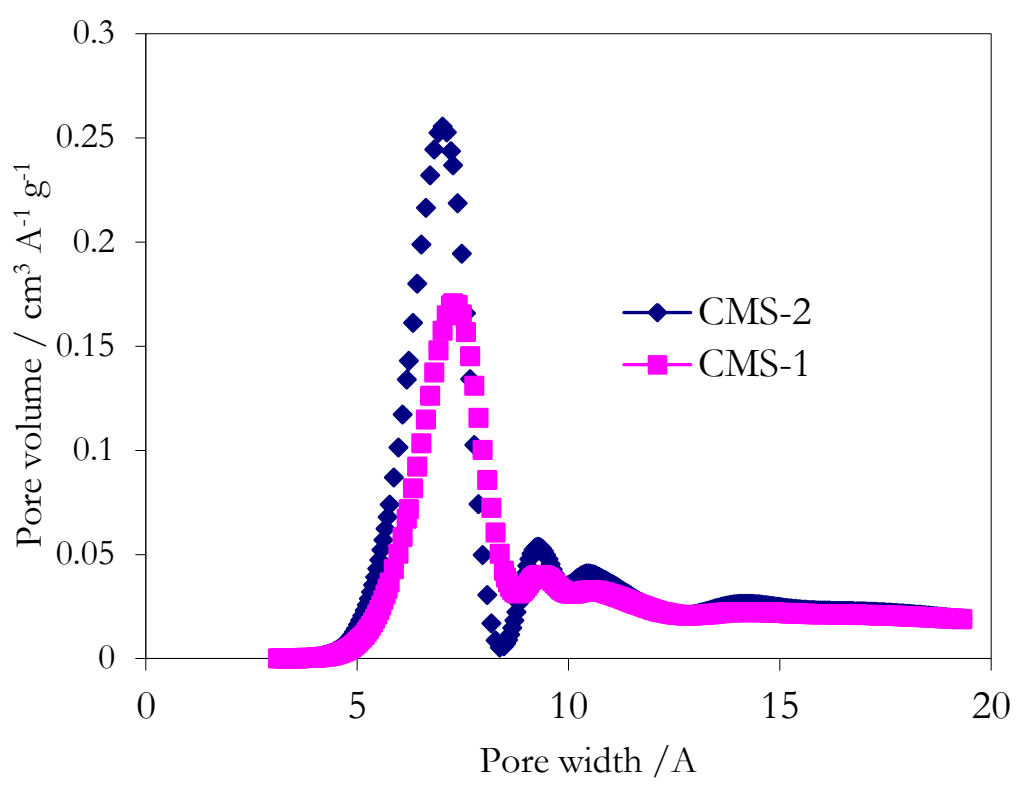

Fig. 2(b). Pore size distribution of CMS-1 and CMS-2 produced by pyrolysis of phenolic polymers at $850^{\circ} \mathrm{C}$.

Figure 2 (b) shows the PSD of two CMSs at carbonization temperature of $850^{\circ} \mathrm{C}$. The CMS-2 exhibits a higher peak at $c a .0 .7 \mathrm{~nm}$ pore size compared to the CMS-1 suggesting narrower pore size distribution with substantially large micropores. Comparing Fig. 2(a) and Fig. 2(b) indicates that the pore property of CMS-2 is more or less preserved while the character of CMS-1 is drastically altered when increasing the carbonization temperature from 800 to $850^{\circ} \mathrm{C}$. The change of the pore size distribution of the porous carbon can be attributed to the change of the heat resistance of the precursor.

\subsection{Adsorption Capacity Test}

The material characterizations show the outstanding properties of CMS-2 as highly microporous and thermally stable carbon. The efficacy of material was then tested as molecular sieve for $\mathrm{CO}_{2} / \mathrm{CH}_{4}$ separation. For this, the uptake capacity and kinetic selectivity toward $\mathrm{CO}_{2}$ and $\mathrm{CH}_{4}$ gases were determined and the data obtained is presented as an adsorption isotherm curve. Uptake capacity of the CMS-2 toward $\mathrm{CH}_{4}$ and $\mathrm{CO}_{2}$ at three different temperatures $(293,303$ and $323 \mathrm{~K}$ ) is presented in Fig. 3a and 3b, respectively. More or less a linear curve of equilibrium uptake is seen and a higher uptake capacity of the gases results at lower adsorption temperature. Comparing Fig. 3(a) and 3(b) indicates that the uptake capacity of the CMS-2 for methane is about $50 \%$ of the adsorption capacity of carbon dioxide. This concludes the molecular sieving characters of CMS-2 which are useful for the $\mathrm{CO}_{2} / \mathrm{CH}_{4}$ separation. Table 2 shows comparison of the uptake capacity of different molecular sieves such as natural polymer-derived activated carbon (activated carbon (AC) and microwave activated carbon (MAC)), synthetic polymer based carbon (ordered mesoporous carbon $(\mathrm{OMC})]$ and Ajax commercial carbon [24, 27-30]. It can be clearly seen that CMS-2 features relatively high adsorption capacities of $\mathrm{CO}_{2}$ and $\mathrm{CH}_{4}$, thus high performance results. 


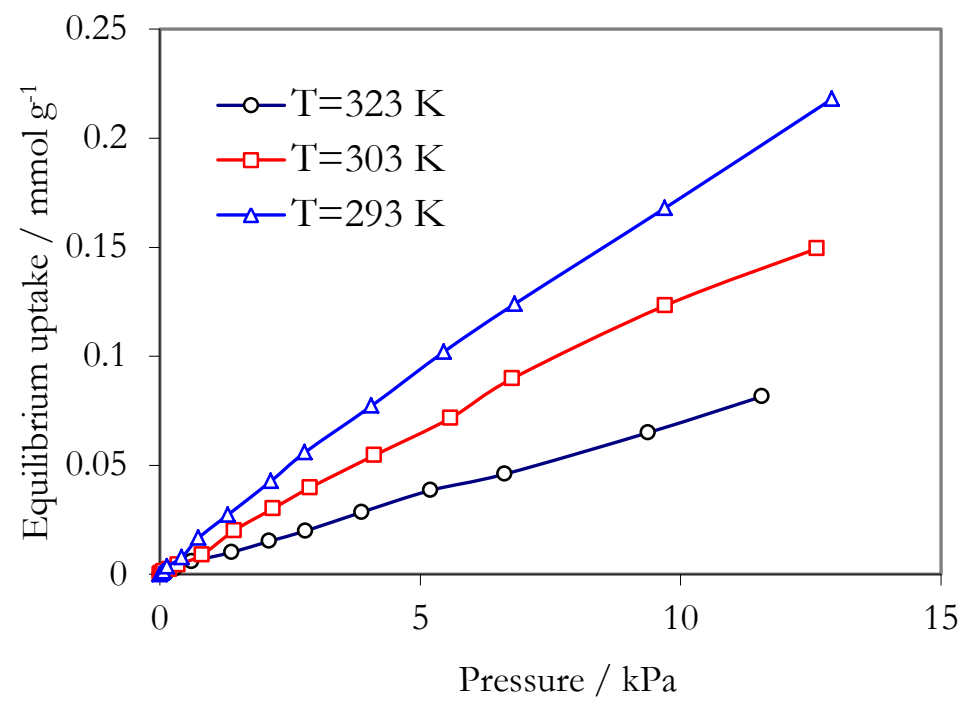

Fig. 3(a). Adsorption isotherm of $\mathrm{CH}_{4}$ on CMS-2 at various temperatures.

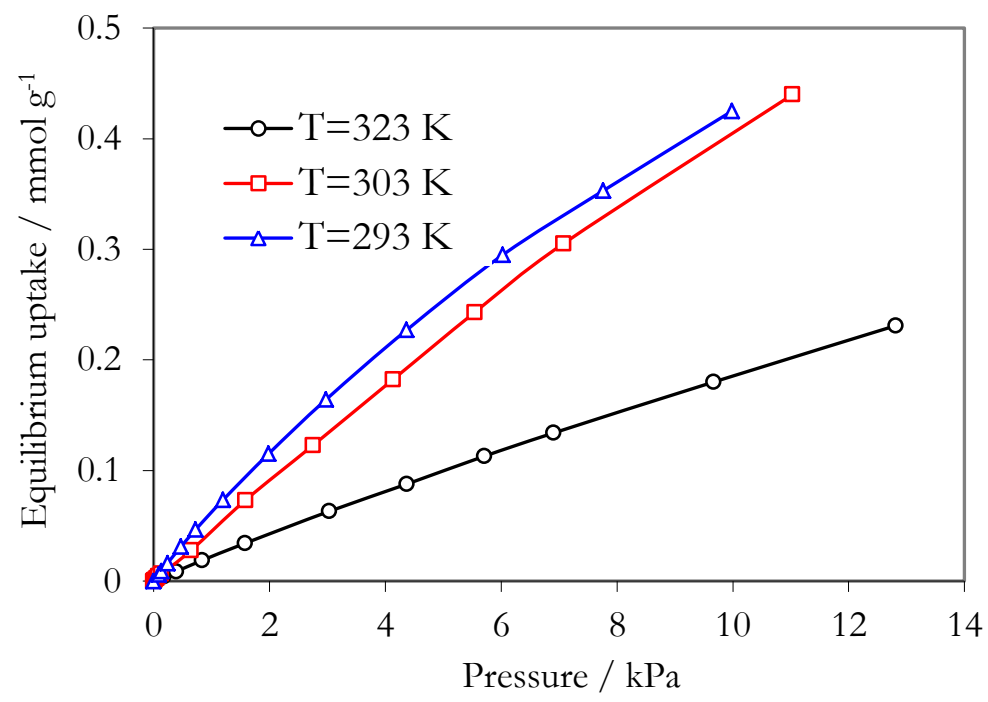

Fig. 3(b). Adsorption isotherm of $\mathrm{CO}_{2}$ on CMS-2 at various temperatures.

By using the equilibrium adsorption of methane and carbon dioxide on the CMS-2 at different temperatures, the heat of adsorption can be determined employing the Clapeyron equation ( $\left.d p / p=\frac{\Delta H}{R} \frac{d T}{T^{2}}\right)$. The heat of adsorption of methane on CMS-2 $(25.2 \mathrm{~kJ} / \mathrm{mol})$ is slightly lower than the heat adsorption of carbon dioxide $(27.4 \mathrm{~kJ} / \mathrm{mol})$. Furthermore, the affinity of the CMS toward the adsorbate is the evaluated by the Henry constant values. The constant increases when increasing adsorption temperature which is in agreement with higher uptake capacity at higher temperature. The remarkably high value in each measurement temperature for $\mathrm{CO}_{2}$ adsorption (ca. 3 time of magnitude in respect to adsorption of $\mathrm{CH}_{4}$ ) indicates the adsorption of carbon dioxide on the CMS is more favorable than methane in the CMS. Thus, when these two gases are present in the system, the CMS could selectively adsorb $\mathrm{CO}_{2}$ abundantly while high amount of $\mathrm{CH}_{4}$ is still in the gas phase. This leads for separation of $\mathrm{CH}_{4}$ from the mixture of $\mathrm{CO}_{2}$ and $\mathrm{CH}_{4}$. All values evaluated from the isotherm measurements are summarized in Table 3 . 
Table 2. Molecular sieves and their uptake capacity at $10 \mathrm{kPa}$.

\begin{tabular}{|c|c|c|c|c|c|}
\hline \multirow[t]{2}{*}{ Molecular sieves } & \multirow{2}{*}{$\begin{array}{c}\text { Specific surface } \\
\text { area } \\
{\left[\mathrm{m}^{2} / \mathrm{g}\right]}\end{array}$} & \multirow{2}{*}{$\begin{array}{c}T \\
{[\mathrm{~K}]}\end{array}$} & \multicolumn{2}{|c|}{$\begin{array}{c}\text { Adsorption capacities } \\
{[\mathrm{mmol} / \mathrm{g}]}\end{array}$} & \multirow[t]{2}{*}{ Reference } \\
\hline & & & $\mathrm{CO}_{2}$ & $\mathrm{CH}_{4}$ & \\
\hline \multirow{3}{*}{ CMS-2 } & \multirow{3}{*}{1774} & 293 & 0.43 & 0.16 & \multirow{3}{*}{ this work } \\
\hline & & 303 & 0.40 & 0.13 & \\
\hline & & 323 & 0.20 & 0.06 & \\
\hline \multirow{4}{*}{ Lignin AC } & \multirow{3}{*}{820} & 273 & 0.51 & 0.10 & \multirow{3}{*}{ [29] } \\
\hline & & 283 & 0.50 & 0.08 & \\
\hline & & 293 & 0.26 & 0.05 & \\
\hline & \multirow{3}{*}{2255} & 278 & 0.50 & 0.18 & \multirow{3}{*}[27]{} \\
\hline \multirow{3}{*}{ OMC } & & 298 & 0.25 & 0.11 & \\
\hline & & 318 & 0.12 & 0.07 & \\
\hline & \multirow{3}{*}{670} & 298 & 0.38 & 0.17 & \multirow{3}{*}[30]{} \\
\hline \multirow[t]{2}{*}{ MAC } & & 308 & 0.35 & 0.17 & \\
\hline & & 323 & 0.22 & 0.10 & \\
\hline $\begin{array}{l}\text { Ajax commercial } \\
\text { carbon }\end{array}$ & 1200 & 303 & 0.37 & 0.11 & [24] \\
\hline Palm shell AC & 1000 & 298 & $0.48^{*}$ & $0.14 *$ & [28] \\
\hline
\end{tabular}

*) uptake capacity at $100 \mathrm{kPa}$

Table 3. Heat of adsorption and Henry constant for $\mathrm{CH}_{4}$ and $\mathrm{CO}_{2}$ in the CMS-2 produced.

\begin{tabular}{lllll}
\hline Adsorbate & $\boldsymbol{\Delta} \mathbf{H}$ & Temperature & Henry constant, & Henry constant, \\
& {$[\mathbf{k J} / \mathbf{m o l}]$} & {$[\mathbf{K}]$} & $\boldsymbol{K}_{p}^{*}$ & 51 \\
\hline $\mathrm{CH}_{4}$ & 25.2 & 293 & $6.5 \times 10^{-5}$ & 43 \\
& & 303 & $5.7 \times 10^{-5}$ & 29 \\
& & 323 & $2.3 \times 10^{-5}$ & 172 \\
$\mathrm{CO}_{2}$ & 27.4 & 293 & $18.2 \times 10^{-5}$ & 149 \\
& & 303 & $16.5 \times 10^{-5}$ & 70 \\
\hline
\end{tabular}

*in: $\mathrm{gmol} /(\mathrm{gram} \times \mathrm{kPa})$

${ }^{* *}$ dimensionless, $K=\left(K_{p} \rho_{p} \mathrm{RT}\right)(1-\varepsilon)$

In this work, the adsorption enthalpies of $\mathrm{CH}_{4}$ and $\mathrm{CO}_{2}$ on CMS-2 are in between 10 to $50 \mathrm{~kJ} \mathrm{~mol}-1$ which are in agreement to the typical adsorptive behaviours of these gases on the porous adsorbent, such as activated carbons $[24,29,30]$ and zeolites [2, 34]. These values of heat of adsorption imply isosteric enthalpies of physic sorption and these low heat values featured by CMS-2 when adsorbing gases are helpful to prevent the reduction of adsorptive amount when performing an adiabatic operation. The Henry constants which indicate affinity of adsorbates are compared to the literature values. While all agreed that the affinity of $\mathrm{CO}_{2}$ is higher than that of $\mathrm{CH}_{4}$ on $\mathrm{CMS}$, the values obtained are relatively higher in the range of 1.3-4 manifolds [24, 27, 30]. The surface properties and a narrow pore size distribution of CMS-2 likely contribute to this good adsorptive characteristic.

\subsection{Kinetics of Gas Uptake Measurement Test}

The apparent diffusivity $\left(D_{a p p}\right)$ of gas through the sample is an important character for to indicate gas separation performances. Therefore, the kinetic study of adsorption of $\mathrm{CO}_{2}$ and $\mathrm{CH}_{4}$ was carried out. Table 4 shows the obtained apparent diffusivity for $\mathrm{CH}_{4}$ and $\mathrm{CO}_{2}$ in the CMS-2 evaluated with the adsorption kinetics model. The ranges of values are $7-17 \times 10^{-7}$ and $1-2.75 \times 10^{-7} \mathrm{~m}^{2} / \mathrm{s}$ when using $\mathrm{CH}_{4}$ and $\mathrm{CO}_{2}$ as adsorbates, respectively at studied temperature between 293 and $323 \mathrm{~K}$. These apparent diffusivity values are in the same order magnitude with the typical diffusivity constant obtained from literatures [24, 29, 35]. The higher temperature leads to more movable molecules, thus showing lower apparent diffusivity. The high separation for $\mathrm{CO}_{2} / \mathrm{CH}_{4}$ is exhibited by high ratio of $D_{a p p}$ between two species which is about 8 . 
Table 4. Adsorbate properties [36-38] and the resulting apparent diffusivity $\left(D_{a p p}\right)$ of $\mathrm{CH}_{4}$ and $\mathrm{CO}_{2}$ in the CMS produced.

\begin{tabular}{ccccccc}
\hline Adsorbate & $\begin{array}{c}\text { Molecule } \\
\text { length } \\
{[\mathrm{nm}]}\end{array}$ & $\begin{array}{c}\text { Molecule } \\
\text { width } \\
{[\mathrm{nm}]}\end{array}$ & $\begin{array}{c}\text { Kinetic } \\
\text { diameter } \\
{[\mathrm{nm}]}\end{array}$ & $\begin{array}{c}\text { Lennard- } \\
\text { Jones force } \\
\text { constant }\end{array}$ & $\begin{array}{c}\text { Temperature } \\
\text { for kinetic test } \\
{[\mathrm{K}]}\end{array}$ & $\begin{array}{c}\text { Resulting } \\
\boldsymbol{D}_{\text {app }} \\
{\left[\mathrm{m}^{2} / \mathrm{s}\right]}\end{array}$ \\
\hline $\mathrm{CH}_{4}$ & - & 0.42 & 0.38 & 137 & 293 & $7.5 \times 10^{-7}$ \\
& & & & & 303 & $9.2 \times 10^{-7}$ \\
$\mathrm{CO}_{2}$ & 0.51 & 0.37 & 0.33 & 190 & 323 & $16.3 \times 10^{-7}$ \\
& & & & & 293 & $1.25 \times 10^{-7}$ \\
& & & & & 303 & $1.58 \times 10^{-7}$ \\
& & & & & 323 & $2.75 \times 10^{-7}$ \\
\hline
\end{tabular}

The molecular sieving characters of carbon material are dictated by many factors such as the pore structure of adsorbent, kinetic diameter of adsorbate, affinity of adsorbate toward carbon surface and molecular interaction of adsorbate. It is known that pore size distribution with high portion below ultramicropore range $(<0.7 \mathrm{~nm})$ like featured by CMS-2 is essential to introduce good molecular sieving characters [4]. Furthermore, location and number of pore mouth (pore constriction) also plays important roles, although these parameters are difficult to be quantitatively determined. The next aspect is the kinetic diameter which is close to the molecular sieving dimension of gas, thus sensitively measuring ability of gas to move in highly restrictive environments. $\mathrm{CO}_{2}$ features smaller kinetic diameter $(0.33 \mathrm{~nm})$ than $\mathrm{CH}_{4}(0.38$ $\mathrm{nm}$ ) as shown in Table 4, but due to the shape of molecules (dimension of gases given in the table), the sphere shape of methane make this molecule more mobile than $\mathrm{CO}_{2}$ molecule (a linear shape). Furthermore, due to featuring relatively high polarity, $\mathrm{CO}_{2}$ shows higher affinity on carbon surface and higher interaction between molecules (see Lennard-Jones constant in Table 4) [38]. Consequently, the mobility of adsorbed molecules of carbon dioxide is slower, but this molecule is more likely to be adsorbed on the carbon surface. Considering all aspects makes it obvious why there is the high difference of diffusivities of $\mathrm{CO}_{2}$ and $\mathrm{CH}_{4}$ in $\mathrm{CMS}-2$, inducing to high separation for these two gases.

\section{Conclusions}

The feasibility of preparing effective sieving properties of $\mathrm{CMS}$ for $\mathrm{CO}_{2} / \mathrm{CH}_{4}$ separation has been examined. In this method, CMSs were prepared by controlled pyrolysis of phenol formaldehyde $p$-tert-butyl phenol polymeric resin as a precursor. In the synthesis of the precursor, para-tert-butyl phenol was used in combination with phenol in order to obtain thermally stable precursor. At high carbonization temperature, the porous carbon prepared by PFTBP (phenol formaldehyde para-tert-butyl phenol) polymer exhibited higher surface area than that of conventional phenol formaldehyde polymer. The indication shows that when the thermally stable polymeric precursor is exposed to high temperature during carbonization process only hydrogen and oxygen are removed by pyrolytic decomposition and left behind a rigid polymer network formed microporous carbon with fine pores. We demonstrated that the resulting carbon exhibits molecular sieving character with kinetic selectivity $\left(D_{\mathrm{CO} 2} / D_{\mathrm{CH} 4}\right)$ as high as 8 . Therefore, the material is promising as carbon molecular sieve.

\section{References}

[1] N. Alvarez-Gutierrez, S. Garcia, M. V. Gil, F. Rubiera, and C. Pevida, "Dynamic performance of biomass-based carbons for $\mathrm{CO}_{2} / \mathrm{CH}_{4}$ separation. Approximation to a Pressure swing adsorption process for biogas upgrading," Energy Fuels, vol. 30, pp. 5005-5015, June 2016.

[2] S. Cavenati, C. A. Grande, and A. E. Rodrigues, "Adsorption equilibrium of methane, carbon dioxide, and nitrogen on zeolite 13x at high pressures," Journal of chemical engineering data, vol. 49, pp. 1095-1101, May 2004.

[3] W. Conway, X. G. Wang, D. Fernandes, R. Burns, G. Lawrance, G. Puxty, and M. Maeder, “Toward the understanding of chemical absorption processes for post-combustion capture of carbon dioxide: 
electronic and steric considerations from the kinetics of reactions of $\mathrm{CO}_{2}(\mathrm{aq})$ with sterically hindered amines," Environmental Science \& Technology, vol. 47, pp. 1163-1169, Jan. 2013.

[4] A. Silvestre-Albero, S. Rico-Francés, F. Rodríguez-Reinoso, A. M. Kern, M. Klumpp, B. J. M. Etzold, and J. Silvestre-Albero, "High selectivity of TiC-CDC for $\mathrm{CO}_{2} / \mathrm{N}_{2}$ separation," Carbon, vol. 59, pp. 221-228, Jan. 2013.

[5] C. R. Reid and K. M. Thomas, "Adsorption of gases on a carbon molecular sieve used for air separation: Linear adsorptives as probes for kinetic selectivity," Langmuir, vol. 15, pp. 3206-3218, Apr. 1999.

[6] E. N. Hoffman, G. Yushin, B. G. Wendler, M. W. Barsoum, and Y. Gogotsi, "Carbide-derived carbon membrane," Mater. Chem. Phys., vol. 112, pp. 587-591, Dec. 2008.

[7] A. D. Wiheeb, Z. Helwani, J. Kim, and M. R. Othman, "Pressure swing adsorption technologies for carbon dioxide capture," Sep. Purif. Rev., vol. 45, pp. 108-121, Aug. 2015.

[8] P. Krawiec, E. Kockrick, L. Borchardt, D. Geiger, A. Corma, and S. Kaskel, "Ordered mesoporous carbide derived carbons: Novel materials for catalysis and adsorption," J. Phys. Chem. C, vol. 113, pp. 7755-7761, May 2009.

[9] A. Y. Lo, C. T. Hung, N. Y. Yu, C. T. Kuo, and S. B. Liu, "Syntheses of carbon porous materials with varied pore sizes and their performances as catalyst supports during methanol oxidation reaction," Appl Energ, vol. 100, pp. 66-74, Dec. 2012.

[10] J. Glasel, J. Y. Diao, Z. B. Feng, M. Hilgart, T. Wolker, D. S. Su, and B. J. M. Etzold, "Mesoporous and graphitic carbide-derived carbons as selective and stable catalysts for the dehydrogenation reaction," Chem. Mater., vol. 27, pp. 5719-5725, Aug. 2015.

[11] E. Antolini, "Carbon supports for low-temperature fuel cell catalysts," Appl. Catal., B, vol. 88, pp. 124, Oct. 2009.

[12] B. Hasse, J. Glasel, A. M. Kern, D. Y. Murzin, and B. J. M. Etzold, "Preparation of carbide-derived carbon supported platinum catalysts," Catal. Today, vol. 249, pp. 30-37, July 2015.

[13] J. Rodrlguez-Mirasol, T. Cordero, and J. J. Rodriguez, "Activated carbons from $\mathrm{CO}_{2}$ partial gasification of eucalyptus kraft lignin," Energy Fuels, pp. 133-138, Mar. 1993.

[14] F. Zhang, H. Ma, J. Chen, G. D. Li, Y. Zhang, and J. S. Chen, "Preparation and gas storage of high surface area microporous carbon derived from biomass source cornstalks," Bioresour. Technol., vol. 99, pp. 4803-4808, July 2008.

[15] J. Alcaniz-Monge, J. P. Marco-Lozar, and D. Lozano-Castello, "Monolithic carbon molecular sieves from activated bituminous coal impregnated with a slurry of coal tar pitch," Fuel Process. Technol, vol. 95, pp. 67-72, Mar. 2012.

[16] C. Tangsathitkulchai, S. Junpirom, and J. Katesa, "Comparison of kinetic models for $\mathrm{CO}_{2}$ Gasification of coconut-shell chars: Carbonization Temperature effects on char reactivity and porous properties of produced activated carbons," Engineering Journal, vol. 17, pp. 13-27, 2013.

[17] N. P. Wickramaratne and M. Jaroniec, "Phenolic resin-based carbons with ultra-large mesopores prepared in the presence of poly(ethylene oxide)-poly(butylene oxide)-poly(ethylene oxide) triblock copolymer and trimethyl benzene," Carbon, vol. 51, pp. 45-51, Jan. 2013.

[18] K. Nakagawa, S. R. Mukai, K. Tamura, and H. Tamon, "Mesoporous activated carbons from phenolic resins," Chemical Engineering Research \& Design, vol. 85, pp. 1331-1337, Sep. 2007.

[19] G. C. Laredo, E. Meneses, J. Castillo, J. O. Marroquin, and F. Jimeenez-Cruz, "Adsorption equilibrium and kinetics of branched octane isomers on a polyvinylidene chloride-based carbon molecular sieve," Energy Fuels, vol. 22, pp. 2641-2648, Aug. 2008.

[20] X. Ning and W. J. Koros, "Carbon molecular sieve membranes derived from matrimid (R) polyimide for nitrogen/methane separation,” Carbon, vol. 66, pp. 511-522, Jan. 2014.

[21] I. Prasetyo, Rochmadi, T. Ariyanto, and R. Yunanto, "Simple method to produce nanoporous carbon for various applications by pyrolysis of specially synthesized phenolic resin," Ind. J. Chem, vol. 13, pp. 95-100, Jan. 2013.

[22] K. Lenghaus, G. G. H. Qiao, D. H. Solomon, C. Gomez, F. Rodriguez-Reinoso, and A. SepulvedaEscribano, "Controlling carbon microporosity: the structure of carbons obtained from different phenolic resin precursors," Carbon, vol. 40, pp. 743-749, June 2002.

[23] T. Zhang, W. P. Walawender, and L. T. Fan, "Preparation of carbon molecular sieves by carbon deposition from methane," Bioresour. Technol., vol. 96, pp. 1929-35, Nov. 2005.

[24] I. Prasetyo and D. D. Do, "Adsorption rate of methane and carbon dioxide on activated carbon by the semi-batch constant molar flow rate method," Chem. Eng. Sci., vol. 53, pp. 3459-3467, Oct. 1998. 
[25] R. F. P. M. Moreira and A. E. Rodrigues, "Polyfurfuryl alcohol-derived carbon molecular sieves," Lat. Am. Appl. Res., vol. 31, pp. 391-396, Oct. 2001.

[26] A. Kumar and R. K. Gupta, Fundamentals of Polymers, 1st ed. Singapore: McGraw-Hill Book Co., 1998, pp. 96-98.

[27] B. Yuan, X. Wu, Y. Chen, J. Huang, H. Luo, and S. Deng, "Adsorption of $\mathrm{CO}_{2}, \mathrm{CH}_{4}$, and $\mathrm{N}_{2}$ on ordered mesoporous carbon: Approach for Greenhouse gases capture and biogas upgrading," Environmental Science \& Technology, vol. 47, pp. 5474-5480, Apr. 2013.

[28] M. K. Aroua, W. Mohd, A. W. Daud, C. Y. Yin, and D. Adinata, "Adsorption capacities of carbon dioxide, oxygen, nitrogen and methane on carbon molecular basket derived from polyethyleneimine impregnation on microporous palm shell activated carbon," Sep. Purif. Technol., vol. 62, pp. 609-613, Mar. 2008.

[29] Y. Sun, G. Yang, J.-p. Zhang, Y. Wang, and M.-s. Yao, "Activated carbon preparation from lignin by $\mathrm{H}_{3} \mathrm{PO}_{4}$ activation and its application to gas separation," Chem. Eng. Technol,, vol. 35, pp. 309-316, Oct. 2011.

[30] H. Yi, F. Li, P. Ning, X. Tang, J. Peng, Y. Li, and H. Deng, "Adsorption separation of $\mathrm{CO}_{2}, \mathrm{CH}_{4}$, and $\mathrm{N}_{2}$ on microwave activated carbon," Chem. Eng. J., vol. 215-216, pp. 635-642, Nov. 2013.

[31] T. Ariyanto, G.-R. Zhang, F. Riyahi, J. Gläsel, and B. J. M. Etzold, "Controlled synthesis of core-shell carbide-derived carbons through in situ generated chlorine," Carbon, vol. 115, pp. 422-429, Jan. 2017.

[32] T. Ariyanto, A. M. Laziz, J. Glasel, G. R. Zhang, J. Garbes, and B. J. M. Etzold, "Producing high quality carbide-derived carbon from low quality byproducts stemming from $\mathrm{SiC}$ production," Chem. Eng. J., vol. 283, pp. 676-681, Jan. 2016.

[33] T. Ariyanto, B. Dyatkin, G. R. Zhang, A. Kern, Y. Gogotsi, and B. J. M. Etzold, "Synthesis of carbon core-shell pore structures and their performance as supercapacitors," Micropor. Mesopor. Mater., vol. 218, pp. 130-136, Dec. 2015.

[34] P. Li and F. Handan Tezel, "Adsorption separation of $\mathrm{N}_{2}, \mathrm{O}_{2}, \mathrm{CO}_{2}$ and $\mathrm{CH}_{4}$ gases by $\beta$-zeolite," Micropor. Mesopor. Mater., vol. 98, pp. 94-101, Oct. 2007.

[35] R. Babarao and J. Jiang, "Diffusion and separation of $\mathrm{CO}_{2}$ and $\mathrm{CH}_{4}$ in silicalite, $\mathrm{C} 168$ schwarzite, and IRMOF-1: A comparative study from molecular dynamics simulation," Langmuir, vol. 24, pp. 54745484, Feb. 2008.

[36] R. W. Baker, Membrane Technology and Applications, 2nd ed. West Sussex, England: John Wiley \& Sons, Ltd, 2004.

[37] J.-J. Shieh and T. S. Chung, "Gas Permeability , diffusivity, and solubility of poly ( 4 - Vinylpyridine ) film,” J. Polym. Sci. B : Polym. Phys., vol. 37, pp. 2851-2861, June 1999.

[38] R. B. Bird, W. E. Stewart, and E. N. Lightfoot, Transport Phenomena, 2nd ed. New York: J. Wiley, 2002. 